\title{
Exosomes mediate hepatitis B virus (HBV) transmission and NK-cell dysfunction
}

\author{
Yinli Yang${ }^{1}$, Qiuju Han ${ }^{1}$, Zhaohua Hou ${ }^{1}$, Cai Zhang${ }^{1}$, Zhigang Tian ${ }^{2}$ and Jian Zhang1
}

Evidence suggests that exosomes can transfer genetic material between cells. However, their roles in hepatitis B virus (HBV) infection remain unclear. Here, we report that exosomes present in the sera of chronic hepatitis B (CHB) patients contained both HBV nucleic acids and HBV proteins, and transferred HBV to hepatocytes in an active manner. Notably, HBV nucleic acids were detected in natural killer (NK) cells from both CHB patients and healthy donors after exposure to HBV-positive exosomes. Through real-time fluorescence microscopy and flow cytometry, 1,1'-dioctadecyl-3,3,3',3',-tetramethylindodicarbocyanine, 4-chlorobenzenesulfnate salt (DiD)-labeled exosomes were observed to interact with NK cells and to be taken up by NK cells, which was enhanced by transforming growth factor- $\beta$ treatment. Furthermore, HBV-positive exosomes impaired NK-cell functions, including interferon (IFN)- $\gamma$ production, cytolytic activity, NK-cell proliferation and survival, as well as the responsiveness of the cells to poly $(\mathrm{I}: \mathrm{C})$ stimulation. HBV infection suppressed the expression of pattern-recognition receptors, especially retinoic acid inducible gene I (RIG-I), on NK cells, resulting in the dampening of the nuclear factor $\kappa B$ (NF-kB) and p38 mitogen-activated protein kinase pathways. Our results highlight a previously unappreciated role of exosomes in HBV transmission and NK-cell dysfunction during CHB infection.

Cellular \& Molecular Immunology (2017) 14, 465-475; doi:10.1038/cmi.2016.24; published online 30 May 2016

Keywords: CHB; dysfunction; exosome; HBV; NK cells

\section{INTRODUCTION}

Currently, 350 million people suffer from chronic hepatitis B virus (CHBV) infection worldwide. ${ }^{1} \mathrm{CHB}$ infection is generally classified into three phases: the immune-tolerant (IT), immuneactive and inactive phases. ${ }^{2}$ Patients in the IT phase exhibit an immunosuppressive state and face a high risk of developing hepatocellular carcinoma even if their alanine aminotransferase level is normal and liver damage is minimal. ${ }^{3}$

Hepatitis B virus (HBV) contains partially double-stranded deoxyribonucleic acid (DNA). Cellular receptor(s), which are key determinants for HBV entry into host cells, mediate the interaction between the virus and its host cells. A number of potential candidate HBV receptors mediating HBV entry have been described in the past three decades, ${ }^{4}$ and sodium taurocholate co-transporting polypeptide (NTCP) was recently identified as a bonafide receptor for $\mathrm{HBV}$ on human hepatocytes. ${ }^{5}$ However, the receptor-independent transmission of viruses has attracted much attention. Evidence shows that the human immunodeficiency virus (HIV), hepatitis C virus (HCV) and human T-cell lymphotropic virus can be transmitted via exosomes. ${ }^{6}$

Exosomes are a subpopulation of extracellular vesicles that originate from multivesicular bodies (MVBs), which are a type of late endosome with sizes ranging from 30 to $150 \mathrm{~nm}$. These vesicles can be produced by most cell types and are detectable in blood, urine and other body fluids. ${ }^{7}$ Exosomes secreted in the extracellular space mediate cell-to-cell communication by transferring bio-macromolecules, functional proteins and nucleic acids between cells. ${ }^{8,9}$ More recently, Bukong et al. ${ }^{10}$ reported the presence of HCV viral ribonucleic acid (RNA) in exosomes isolated from the plasma of $\mathrm{HCV}$-infected patients, and these exosomes effectively transmitted $\mathrm{HCV}$ to hepatocytes in a receptor-independent manner. Furthermore, Dreux et al. ${ }^{11}$ demonstrated that HCV RNAs were encapsulated within hepatocyte-derived exosomes and transferred to plasmacytoid dendritic cells (DCs) to trigger interferon (IFN)- $\alpha$ production. These studies suggest that exosomes mediate the cell-to-cell

\footnotetext{
${ }^{1}$ Institute of Immunopharmaceutical Sciences, School of Pharmaceutical Sciences, Shandong University, Jinan 250012, China and ${ }^{2}$ School of Life Sciences, University of Science and Technology of China, Hefei 230027, China

Correspondence: Professor J Zhang, MD, PhD, Institute of Immunopharmaceutical Sciences, School of Pharmaceutical Sciences, Shandong University, 44 Wenhua West Road, Jinan 250012, China.

E-mail: zhangj65@sdu.edu.cn

Received: 17 January 2016; Revised: 3 April 2016; Accepted: 4 April 2016
} 
transmission of HCV and act as a potential immune evasion or response mechanism.

Regarding the role of exosomes in HBV infection, it is unclear whether exosomes derived from HBV-infected hepatocytes mediate the transmission of $\mathrm{HBV}$ infection. Li et al. ${ }^{12}$ reported that IFN- $\alpha$-induced antiviral responses were transmitted from liver nonparenchymal cells to HBV-infected hepatocytes via exosomes, and thus restored the antiviral state in hepatocytes. In CHB patients, NK-cell functions are disturbed during persistent HBV infection, displaying lower cytolytic activity and IFN- $\gamma$ secretion. ${ }^{13,14}$ Therefore, it is reasonable to hypothesize that HBV may impair NK-cell function via exosomes.

In this study, we isolated exosomes derived from the serum of $\mathrm{CHB}$ patients in the IT phase. We found that these exosomes contained HBV viral components and induced active infection in naive human hepatocytes. Importantly, HBV components were observed to be transmitted into NK cells by exosomes, resulting in NK-cell dysfunction partly by dampening the nuclear factor $\mathrm{\kappa B}(\mathrm{NF}-\mathrm{\kappa B})$ and $\mathrm{p} 38$ mitogen-activated protein kinase (MAPK) signaling pathways. These findings reveal a previously unappreciated role of HBV-positive exosomes in the regulation of innate immune responses during $\mathrm{CHBV}$ infection.

\section{MATERIALS AND METHODS}

\section{Patient samples}

Peripheral blood samples and clinical assessments were obtained during routine follow-ups of hepatitis patients. CHB patients in the IT phase were admitted to the Qilu Hospital at Shandong University. All patients were negative for other viral infections, including hepatitis D virus, $\mathrm{HCV}$ and HIV, and had no autoimmune liver diseases. An age- and sex-matched control group was composed of healthy subjects. The clinical characteristics of these samples are described in Table 1. In accordance with the Ethics Committee of Shandong University, informed consent was acquired from all participants.

Peripheral blood mononuclear cells (PBMCs) were isolated by Ficoll gradient separation after centrifugation. NK cells were purified by negative selection using a human NK cell isolation

Table 1 Clinical characteristics of the enrolled subjects

\begin{tabular}{lcc}
\hline & $\begin{array}{c}\text { Healthy donors } \\
(\mathbf{H D})(\mathbf{n}=\mathbf{4 8})\end{array}$ & $\begin{array}{c}\text { Chronic hepatitis B } \\
\text { patients (CHB) }(\mathbf{n}=\mathbf{5 2})\end{array}$ \\
\hline Age (range), years & $37(20-57)$ & $39(20-60)$ \\
Male, $n$ (\%) & $30(62.5 \%)$ & $32(61.5 \%)$ \\
ALT U/ml (range) & $22.6 \pm 11.3$ & $31.0 \pm 9.20$ \\
AST U/ml (range) & $22.5 \pm 6.23$ & $24.3 \pm 6.78$ \\
TB $\mu \mathrm{mol} / /$ (range) & - & $12.8 \pm 5.35$ \\
DB $\mu \mathrm{mol} /$ l (range) & - & $4.09 \pm 1.23$ \\
HBsAg-positive (\%) & 0 & $52(100 \%)$ \\
HBeAg-positive (\%) & 0 & $52(100 \%)$ \\
HBcAb-positive (\%) & 0 & $52(100 \%)$ \\
\hline
\end{tabular}

Abbreviations: ALT, alanine transaminase; AST, aspartate transaminase; TB, total bilirubin; DB, direct bilirubin. kit (Miltenyi Biotec, Bergisch Gladbach, Germany) according to the manufacturer's instructions. Cell purity was determined by flow cytometry with anti-CD3 and anti-CD56 antibodies (BD Pharmingen, San Jose, CA, USA) and the purity of the NK cells $\left(\mathrm{CD}^{-} \mathrm{CD}^{-} 6^{+}\right)$was determined to be $>95 \%$.

\section{Cell culture}

K562 and HepG2 cells were cultured in RPMI-1640 medium (GIBCO/BRL, Grand Island, NY, USA), supplemented with $100 \mathrm{U} / \mathrm{ml}$ penicillin, $100 \mathrm{mg} / \mathrm{ml}$ streptomycin and $10 \%$ fetal bovine serum. The human NK cell line NK-92 was cultured as previously described. ${ }^{15}$ The HLCZ01 cell line, a newly established hepatocellular carcinoma cell line supporting the entire life cycles of both HBV and HCV, was cultured as described previously. ${ }^{16}$

\section{Exosome isolation}

Because of the limited volume of each sample, several fresh serum samples from $\mathrm{CHB}$ patients with similar clinical indicators or healthy donors were collected and mixed for exosome isolation. Then, the mixture was centrifuged at $2500 \mathrm{~g}$ for $10 \mathrm{~min}$ at $4{ }^{\circ} \mathrm{C}$ to remove cell debris and then filtered through a $0.2-\mu \mathrm{m}$ filter. The supernatant was ultracentrifuged at $110000 \mathrm{~g}$ for $70 \mathrm{~min}$, followed by one wash with phosphatebuffered saline (PBS). Positive selection of the exosomes was performed using CD63-labeled Dynabeads (Life Technologies, Carlsbad, CA, USA) as per the manufacturer's instructions. For labeling, the exosome solution was incubated with

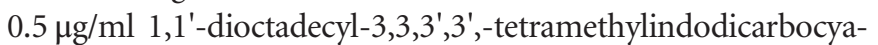
nine, 4-chlorobenzenesulfnate salt (DiD) (Keygenbio, Nanjing, China) for $30 \mathrm{~min}$. The total protein content of the exosomes was determined using a BCA Protein Assay (Beyotime, Beijing, China), and each sample was normalized to a $200 \mu \mathrm{g} / \mathrm{ml}$ concentration in PBS and stored until use.

\section{Electron microscopy}

Anti-CD63 immuno-magnetic bead-bound exosomes were resuspended in PBS and spotted onto formvar-carbon-coated grids (200 mesh). The adsorbed exosomes were fixed with 2\% ( vol/vol) paraformaldehyde for $5 \mathrm{~min}$ at room temperature. Fixation was followed by washes with deionized water, and then the exosomes were directly negatively stained using uranyl acetate. The grids were visualized using a JEM-1011 transmission electron microscope (JEOL, Tokyo, Japan).

NK cells were fixed with $2.5 \%$ glutaraldehyde followed by post-fixation in $1 \% \mathrm{OsO}_{4}$ (Rongbio, Shanghai, China). Dehydration, embedding and thin sectioning $(70 \mathrm{~nm})$ were performed. The samples were stained with uranyl acetate and lead citrate, and finally examined with a JEM-1230 transmission electron microscope (JEOL).

\section{Live-cell fluorescence microscopy}

For live-cell imaging, carboxyfluorescein diacetate succinmidyl ester (CFSE)-labeled HLCZ01 or primary NK cells were plated on a glass-bottom dish (MatTek, Bratislave, Slovak Republic). The live-cell confocal time-lapse sequences were taken on a 
Zeiss Cell Observer s.d. Confocal Microscope (Carl Zeiss Microscopy GmbH, Jena, Germany). Excitation wavelengths of 488 and $639 \mathrm{~nm}$ were selected for CFSE (Beyotime, Nanjing, China) and DiD, respectively. Emission was detected by a $60 \times$ or $100 \times$ oil-immersion objective, and the images were collected in a single $z$-plane. A stage-top incubator was set to $37^{\circ} \mathrm{C}$ and $5 \% \mathrm{CO}_{2}$ to keep the cells alive. All the images were acquired and processed with the Zeiss AxioVision software package (Carl Zeiss Microscopy GmbH).

\section{Analysis of total HBV DNA and RNA}

DNA was extracted from exosomes or cells using a DNA blood mini kit (Qiagen, Valencia, CA, USA) according to the manufacturer's instructions. To remove any viruses derived from the blood that might be adsorbed on the cell surface, isolated leukocytes were treated with DNase I (Sigma Aldrich, St Louis, MO, USA) before DNA and RNA isolation. The level of HBVrelaxed circular DNA (rcDNA) or HBV covalently closed-circular DNA (cccDNA) was detected by polymerase chain reaction (PCR) as described previously. ${ }^{17}$ For PCR detection of $\mathrm{HBV}$ cccDNA, the total DNA was digested with S1 nuclease (Invitrogen, Carlsbad, CA, USA). HBV virus loading was also quantified by quantitative PCR according to the instructions for the Diagnostic Kit for Quantification of HBV DNA (Da-An, Guangzhou, China). The total RNA of exosomes or cells was isolated using TRIzol (Invitrogen, Carlsbad, CA, USA) according to manufacturer's instructions. The extracted RNA was also treated with DNase I to remove the contaminated HBV DNA before reverse transcription using M-MLV reverse transcriptase (Invitrogen, Carlsbad, CA, USA). Meanwhile, the reverse transcriptase-negative control was measured to evaluate the contaminated DNA-to-RNA ratio and the elimination efficiency of DNase I. The $H B V X$ and $S / P$ genes were analyzed using reverse transcription polymerase chain reaction (RT-PCR). The PCR primer sequences are provided in Supplementary Table 1.

\section{Immunofluorescence and immunohistochemistry}

HLCZ01 cells were pulsed with $10 \mu \mathrm{g}$ of DiD-labeled exosomes per $5 \times 10^{4}$ cells for $30 \mathrm{~min}$, then washed in PBS and stained with 4',6-diamidino-2-phenylindole and imaged with an Olympus IX-71 microscope (Olympus, Tokyo, Janpan). Subsequently, HLCZ01 cells were pulsed with DiD-labeled exosomes for $24 \mathrm{~h}$, washed in PBS, and then cultured in fresh medium for another $24 \mathrm{~h}$. Then, heaptitis B core antigen ( $\mathrm{HBcAg}$ ) and hepatitis e antigen (HBeAg) were visualized by staining with rabbit $\alpha-\mathrm{HBc}$ or $\alpha$-HBs Abs (Genetech, Shanghai, China), followed by Envision System HRP detection staining (Genetech, Shanghai, China) performed using the manufacturer's protocol. Images were taken with an Olympus IX-71 Inverted microscope (Olympus).

\section{Flow cytometric analysis}

Multiparameter flow cytometry was performed according to a standard protocol, and the data were acquired using a FACSCalibur flow cytometer and analyzed using FlowJo software (Treestar Inc., Ashland, OR, USA). For CD107a staining,
NK cells were incubated with $10 \mu \mathrm{g} / \mathrm{ml}$ Brefeldin A and $6 \mu \mathrm{g} / \mathrm{ml}$ monensin (Sigma Aldrich) in the presence of anti-human CD107a antibodies for $4 \mathrm{~h}$ and then surface stained for CD3 and CD56. For intracellular staining, the NK cells were stimulated with or without $100 \mu \mathrm{g} / \mathrm{ml}$ poly(I:C) (Sigma Aldrich) and $200 \mathrm{U} / \mathrm{ml}$ rhIL-2 (Changsheng, Changchun, China) for $20 \mathrm{~h}$, and then $10 \mu \mathrm{g} / \mathrm{ml}$ Brefeldin A and $6 \mu \mathrm{g} / \mathrm{ml}$ monensin were added. The cells were harvested $4 \mathrm{~h}$ later and then washed, fixed and permeabilized. Surface or intracellular staining was performed using the following anti-human mAbs: AlexaFluor 488-labeled IgG isotype control and anti-CD3; Phycoerythrin (PE)-labeled IgG isotype control, anti-CD107a, anti-IFN- $\gamma$, anti-TNF- $\alpha$, anti-perforin, anti-GramB, anti-NKG2A, anti-NKp44, anti-NKp46, anti-2B4, anti-TLR3, anti-TLR7 and anti-TLR9; PE-Cy5-labeled IgG isotype control and anti-CD56; APC-labeled IgG isotype control, anti-NKG2D and antiDNAM-1 (BD Biosciences, San Jose, CA, USA). RIG-I, p-p38, and $\mathrm{p}-\mathrm{NF}-\mathrm{\kappa B}$ were tested by primary (Cell Signaling Technology, Danvers, MA, USA) and secondary antibodies (PE-labeled goat anti-rabbit IgG). Exosomes labeled with anti-CD81-peridinin chlorophyll-eFluor 710 (eBioscience, San Diego, CA, USA) were
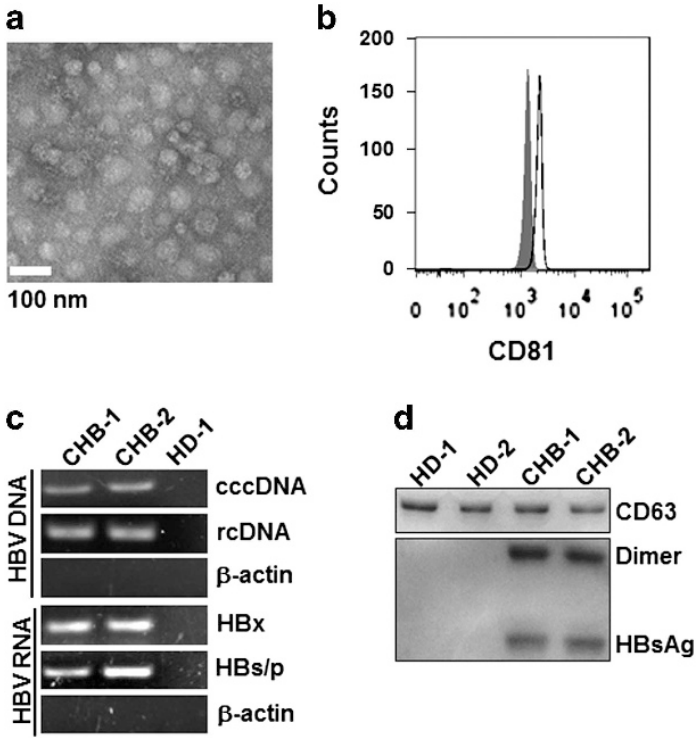

Figure 1 Exosomes derived from $\mathrm{CHB}$ patients contained viral components. (a) Electron microscope image of purified exosomes from $\mathrm{CHB}$ serum. Scale bar, $100 \mathrm{~nm}$. (b) CD81 protein was used to identify the exosomes isolated from $\mathrm{CHB}$ serum using flow cytometry. The shaded histograms represent the isotype control. (c) HBV DNA (rcDNA and cccDNA) and RNA (HBx and $\mathrm{HBs} / \mathrm{p}$ ) in exosomes isolated from $\mathrm{CHB}$ serum were detected using PCR and RT-PCR, respectively. (d) Western blot analysis of $\mathrm{HBsAg}$ and $\mathrm{CD} 63$ in exosomes from $\mathrm{HD}$ and $\mathrm{CHB}$ patient serum ( $10 \mu \mathrm{g} /$ well). (Because of the limited volume of each sample, six fresh serum samples from CHB patients or healthy donors were harvested and mixed for exosome isolation). One representative of at least three independent experiments is shown. CHB, chronic hepatitis B; HBV, hepatitis B virus; DNA, deoxyribonucleic acid; rcDNA, relaxed circular DNA; cccDNA, closed-circular DNA; RNA, ribonucleic acid; PCR, polymerase chain reaction; RT-PCR, reverse transcription polymerase chain reaction; $\mathrm{HD}$, healthy donors. 
evaluated using a BD FACSAria II instrument (BD Biosciences). The data were compensated with single fluorochromes and analyzed using FlowJo software (Treestar Inc.).

\section{Exosome capture assay}

NK cells were incubated with DiD-labeled exosomes at 37 or $4{ }^{\circ} \mathrm{C}$ for the indicated time points. Then, the NK cells were extensively washed in PBS, fixed and the percentage of positive cells was analyzed with fluorescence activated cell sorting.

\section{Western blot}

Total protein was prepared by re-suspending the exosomes or NK cells in RIPA buffer (50 mM Tris- $\mathrm{HCl}$ pH 7.4, $150 \mathrm{mM}$ $\mathrm{NaCl}, 0.5 \%$ sodium deoxycholate, $1 \% \mathrm{NP}-40$ and $0.1 \%$ sodium dodecyl sulfate (SDS)) containing a $1 \mathrm{~mm}$ phenlymethylsulfonyl fluoride and protease inhibitor mixture (Roche Applied Science, Mannheim, Germany). The exosome lysates (10 $\mu \mathrm{g} / \mathrm{lane})$ and NK-cell lysates (30 mg/lane) were separated by SDS polyacrylamide gel electrophoresis and transferred onto a polyvinylidene difluoride membrane (Millipore, Billerica, MA, USA), which was blotted with primary antibodies. Rabbit polyclonal anti-RIG-I,

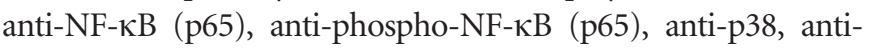
phospho-p38 (Thr 180/Tyr 182), anti-Hep B HBsAg and anti- $\beta$ - actin Abs were purchased from Santa Cruz Biotechnology (Santa Cruz, CA, USA). The anti-CD63 Ab was purchased from Abcam (Abcam, Cambridge, UK). These Abs were detected using HRPconjugated goat-anti-mouse or HRP-conjugated goat-anti-rabbit (Santa Cruz, CA, USA) secondary antibodies. Protein bands were visualized by enhanced chemiluminescence (Millipore, Billerica, MA, USA) and analyzed using ImageLab software (Version 3.0, Bio-Rad, Hercules, CA, USA).

\section{Statistical analysis}

All data were analyzed using GraphPad Prism 5 (GraphPad Software, Inc. La Jolla, CA, USA). When appropriate, Student's $t$-test or one-way analysis of variance with Dunnett's post-test were used to determine statistically significant differences among the control and experimental groups. Significance was defined as ${ }^{\star} P<0.05$ and ${ }^{\star *} P<0.01$.

\section{RESULTS}

\section{Exosomes derived from $\mathrm{CHB}$ patients contained $\mathrm{HBV}$} components

To investigate the capacity of exosomes derived from the serum of $\mathrm{CHB}$ patients to mediate the active transmission of $\mathrm{HBV}$, a
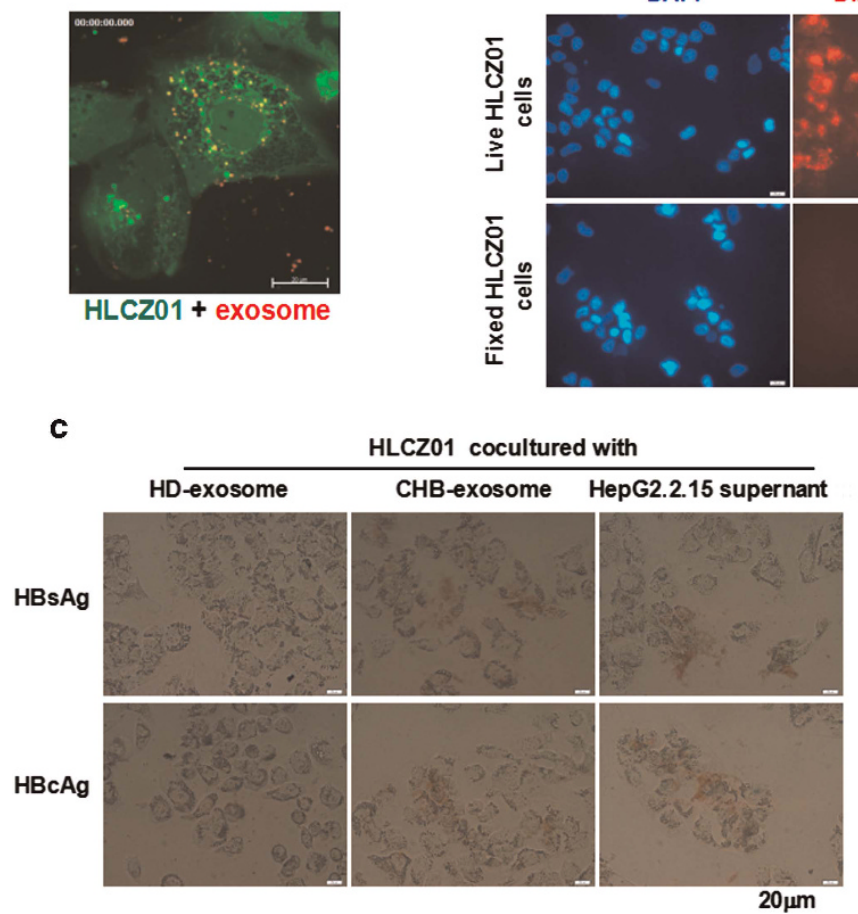

b

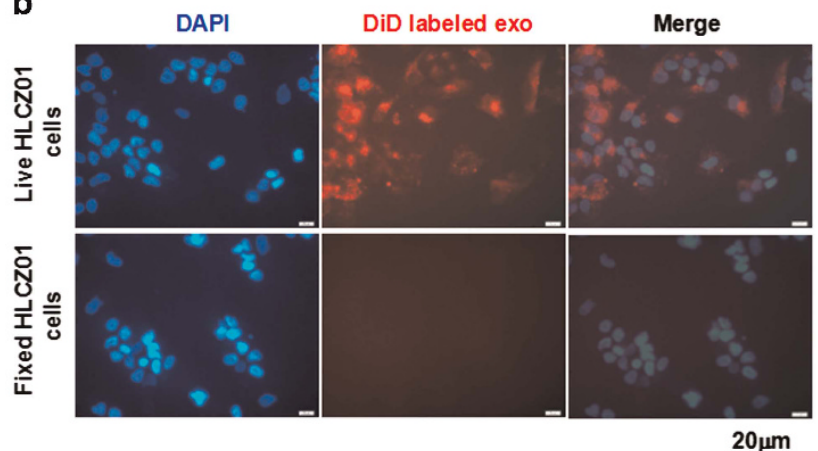

$20 \mu \mathrm{m}$

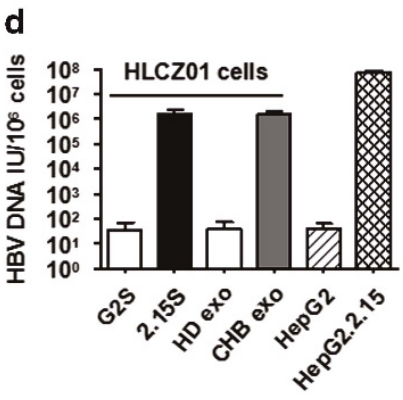

Figure 2 Exosomes can transmit HBV to uninfected hepatoma cells. (a) The confocal image shows the co-localization of CFSE-labeled HLCZO1 cells (green) incubated with DiD-labeled exosomes (red) for $2 \mathrm{~h}$. Scale bar, $20 \mu \mathrm{m}$. (b) Comparison of the ability to take up DiDlabeled exosomes (red) between live HLCZO1 cells and fixed HLCZO1 cells. Scale bar, $20 \mu \mathrm{m}$. (c) Immunocytochemical staining of HBsAg and HBcAg proteins in HLCZO1 cells infected with exosomes or HepG2.2.15 supernatant. Scale bar, $20 \mu \mathrm{m}$. (d) Quantitative PCR analysis of HBV DNA in HLCZO1 cells treated with HD/CHB exosomes, the supernatant of HepG2 cells or the supernatant of HepG2.2.15 cells at an multiplicity of infection of 50 per cell $(n=3)$. HepG2 and HepG2.2.15 cells were used as negative and positive controls, respectively. The results are representative of at least three independent experiments. The data are expressed as the mean \pm s.e.m. ${ }^{*} P<0.05$, ${ }^{* *} P<0.01$. CHB, chronic hepatitis B; DNA, deoxyribonucleic acid; GS, HepG2 supernatant; HBV, hepatitis B virus; HD, healthy donors; 2.15S, HepG2.2.15 supernatant; PCR, polymerase chain reaction. 
a CD63 immuno-magnetic isolation method was used to purify exosomes from the serum of $\mathrm{CHB}$ patients. ${ }^{10}$ The vesicular shape of these exosomes was demonstrated using transmission electron microscopy, and they were $50-100 \mathrm{~nm}$ in size (Figure 1a). Furthermore, these exosomes were characterized by the expression of another exosomal marker, CD81 (Figure 1b). To clarify whether these exosomes contain HBV components, the $\mathrm{HBV}$ nucleic acids and proteins were analyzed. The results showed that HBV DNA and HBV RNA (Figure 1c), as well as HBsAg (Figure 1d), existed in exosomes derived from the serum of $\mathrm{CHB}$ patients. The enzyme-linked immunosorbent assay analysis showed that the levels of HBsAg, HBeAg and HBs antibody were 1.9-5.4 ng, 5.2-1.5 nCU and 3.4-13.0 nIU, respectively. These findings indicate that exosomes present in the serum of $\mathrm{CHB}$ patients contain both HBV nucleic acids and HBV proteins.

Exosomes transmitted HBV to uninfected hepatoma cells To understand whether exosomes derived from CHB patients can transmit HBV to uninfected hepatocytes, CFSE-labeled HLCZ01 cells were incubated with exosomes labeled with DiD and real-time fluorescence microscopy was employed to track the process of exosome entry into HLCZ01 cells (Supplementary Movie S1). The results showed that the exosomes moved rapidly and freely in the medium; meanwhile, the exosomes were inclined to attach to and enter into HLCZ01 cells (Figure 2a, Supplementary Movie S2). The uptake of exosomes by HLCZ01 cells was also confirmed by immunofluorescence. As shown in Figure $2 b$, unlike live cells, paraformaldehyde-fixed cells could not take up DiD-labeled exosomes, confirming that the uptake of exosomes by hepatocytes was an active process. Furthermore, 2 days after exposure to HBV-positive exosomes, HLCZ01 cells were shown to be positive for HBsAg and HBcAg using an immunohistochemistry assay (Figure 2c). The level of these antigens and HBV viral loading was comparable to that of HLCZ01 cells treated with the supernatants from HepG2.2.15 cells, a cell line derived from HepG2 cells transfected with a plasmid carrying two head-to-tail copies of the HBV genome from HBV DNA serotype ayw (Figure 2d). These results indicate that exosomes function as efficiently as free virus in transmitting $\mathrm{HBV}$ infection to hepatocytes.
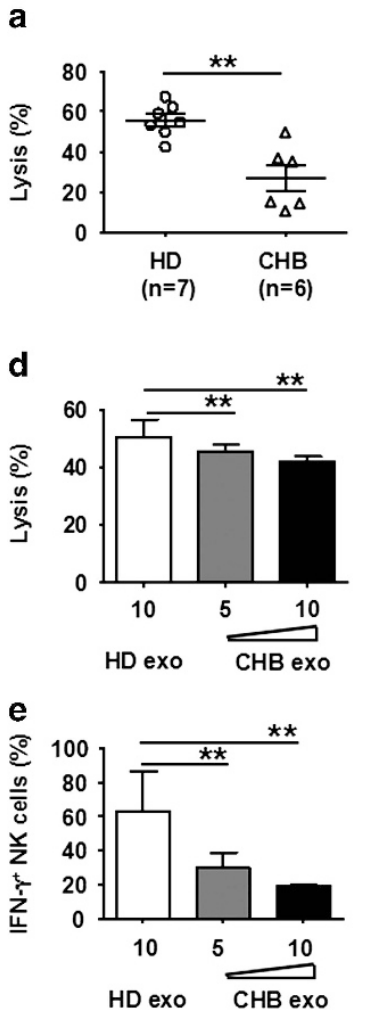
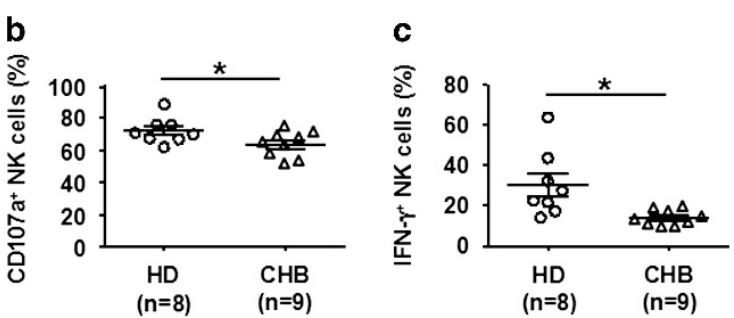

f
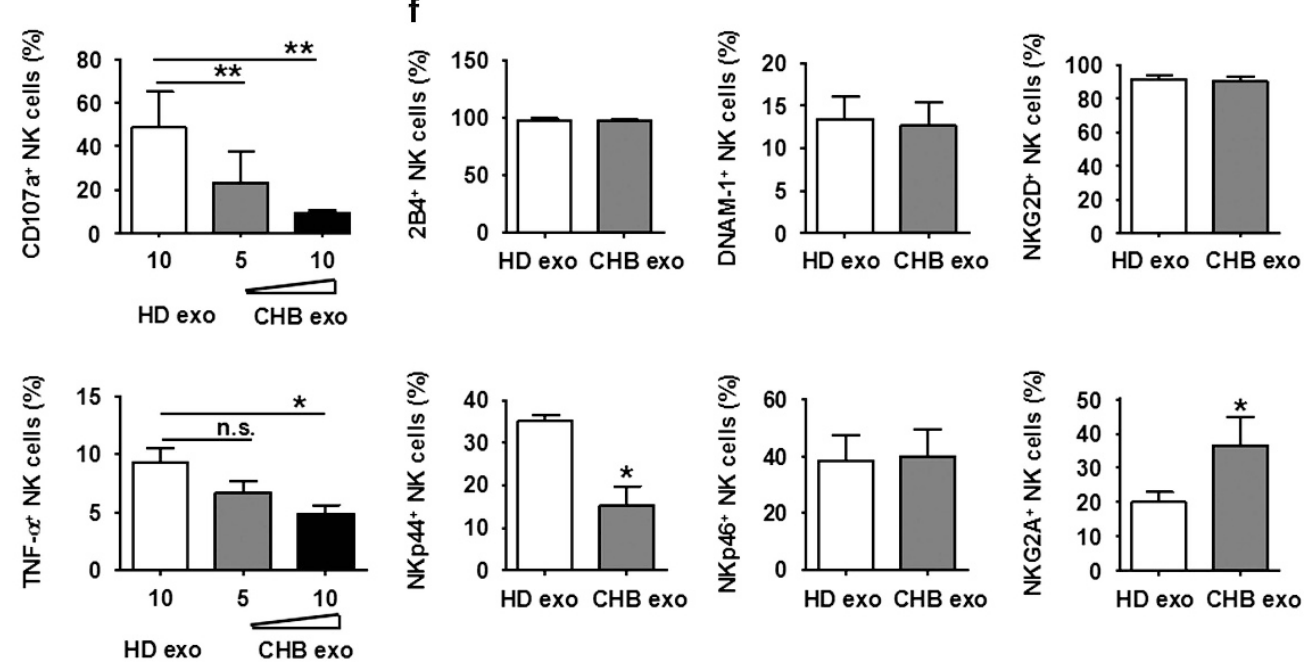
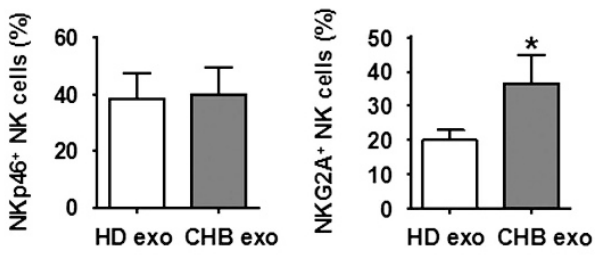

Figure 3 Exosomes derived from CHB patients affected NK cell function. PBMCs from HD and CHB patients were used to determine NK cell-mediated cytotoxicity against K562 cells using the 3-(4,5-cimethylthiazol-2-yl)-2,5-diphenyl tetrazolium bromide (MTT) method (a), and the production of $\mathrm{CD} 107 \mathrm{a}$ (b) and IFN- $\gamma$ (c) in $\mathrm{CD}^{2} 6^{+} \mathrm{CD} 3^{-} \mathrm{NK}$ cells was analyzed using flow cytometry. (d) NK cells isolated from HD were treated with exosomes ( 5 or $10 \mu \mathrm{g} / \mathrm{ml}$ ) from CHB or HD. Then, the cytotoxicity against $\mathrm{K} 562$ cells was determined by CFSE/7AAD assay (left) and CD107a production was tested by flow cytometry (right). (e) IFN- $\gamma$ and TNF- $\alpha$ production by NK cells treated as in $\mathbf{d}$ were determined by flow cytometry. (f) The expression of activating receptors and inhibitory receptors on NK cells treated with CHB exosomes $(10 \mu \mathrm{g} / \mathrm{ml})$ was determined by fluorescence activated cell sorting (FACS) analysis. The results are representative of three independent experiments. The data are expressed as the mean \pm s.e.m. ${ }^{*} P<0.05,{ }^{*} P<0.01$. CHB, chronic hepatitis B; HD, healthy donors; NK, natural killer; PBMCs, peripheral blood mononuclear cells. 


\section{Exosomes derived from $\mathrm{CHB}$ patients affected NK-cell functions}

NK cells are the major cytolytic effector cells in PBMCs in the absence of previous stimulation. Similar to previous reports, ${ }^{18}$ we observed that the cytotoxicity mediated by NK cells from CHB patients against K562 cells was suppressed compared to the cytotoxicity mediated by NK cells from healthy donors (Figure 3a). This observation was accompanied by a decrease in the degranulation molecule CD107a (Figure 3b) and the expression of IFN- $\gamma$ (Figure 3c), indicating that HBV infection suppresses NK-cell function. We further investigated whether HBV disturbed NK-cell function via exosomes. Primary NK cells from healthy donors were incubated with the exosomes derived from $\mathrm{CHB}$ patients for 2 days. NK cell-mediated cytotoxicity, CD107a, IFN- $\gamma$ and the tumor necrosis factor (TNF)- $\alpha$ production of these NK cells were significantly lower than those of NK cells incubated with exosomes derived from healthy volunteers (Figures $3 \mathrm{~d}$ and e). The expression of the activating receptor NKp44 on NK cells was significantly reduced by $\mathrm{CHB}$ exosomes, while the expression of the inhibitory receptor NKG2A was upregulated (Figure 3f). These data suggest that exosomes derived from $\mathrm{CHB}$ patients contribute to NK-cell dysfunction.

\section{Exosomes-mediated HBV transmission into NK cells}

Subsequently, we clarified whether exosomes derived from CHB patients disturb NK-cell functions by shuttling HBV into NK cells. First, we evaluated the presence of HBV DNA and HBV RNA in primary NK cells purified from the PBMCs of CHB patients. As shown in Figure 4a, HBV rcDNA, but not cccDNA, was observed in these NK cells, along with $\mathrm{HBV}$ RNA (HBx and HBs/p), using PCR or RT-PCR analysis. Simultaneously, viral inclusion-like particles were observed in the cytoplasm of NK cells from $\mathrm{CHB}$ patients under electron microscopy (Figure 4b). On the basis of the evidence that all leukocyte subpopulations are able to take up the exosomes released by tumor cells, ${ }^{19}$ NK cells from healthy donors were incubated with exosomes derived from $\mathrm{CHB}$ patients. Real-time fluorescence microscopy (Figure 4c, Supplementary Movie S3) and flow cytometric analysis (Figure 4d) showed a

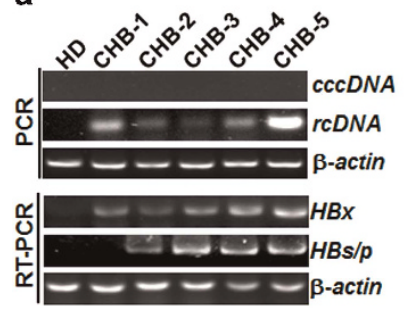

C b

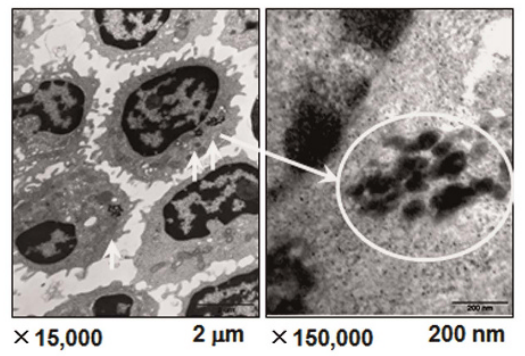

d

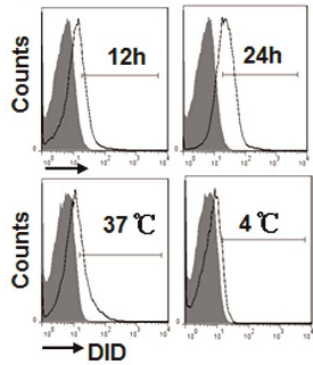

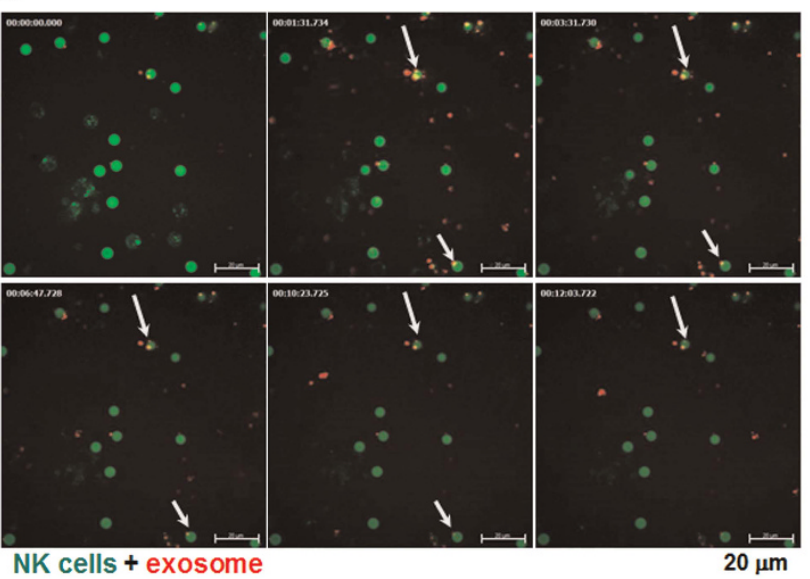
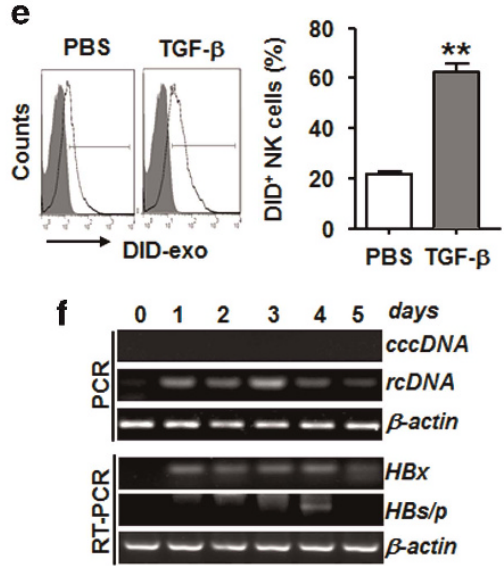

Figure $4 \mathrm{HBV}$ can be transmitted into NK cells through exosomes. (a) Identification of HBV DNA ( $r$ CDNA and cccDNA) and HBV RNA ( $\mathrm{HBx}$ and $\mathrm{HBs} / \mathrm{p}$ ) in NK cells isolated from HD and CHB patients. (b) Transmission electron microscopy of ultrathin sections was used to observe freshly isolated NK cells from CHB patients with high virus loading. Cytoplasmic inclusion bodies with irregular electron density are shown on the left and middle panels (arrows and loop). Scale bar, $2 \mu \mathrm{m}$ and $200 \mathrm{~nm}$. (c) Confocal images of the co-localization of CFSE-labeled (green) primary NK cells from HD incubated with DiD-labeled exosomes (red) for $3 \mathrm{~h}$. Scale bar, $20 \mu \mathrm{m}$. (d) The uptake of DiD-labeled exosomes by primary NK cells after 12 or $24 \mathrm{~h}$ incubation at 37 or $4{ }^{\circ} \mathrm{C}$ was determined by flow cytometry. (e) TGF- $\beta$ ( $5 \mathrm{ng} / \mathrm{ml}$ ) enhanced the ability of primary NK cells to take up DiD-labeled exosomes (red). (f) Analysis of HBV DNA (rcDNA and cccDNA) and RNA $(\mathrm{HBx}$ and $\mathrm{HBs} / \mathrm{p})$ in primary $\mathrm{NK}$ cells from $\mathrm{HD}$ infected with exosomes derived from $\mathrm{CHB}$ serum for $0-5$ days. The results are representative of at least three independent experiments. The data are expressed as the mean \pm s.e.m. ${ }^{*} P<0.05,{ }^{* *} P<0.01$. cccDNA, closed-circular DNA; CHB, chronic hepatitis B; DNA, deoxyribonucleic acid; HBV, hepatitis B virus; HD, healthy donors; NK, natutal killer; rcDNA, relaxed circular DNA; RNA, ribonucleic acid. 
that the exosomes attached to NK cells and then were taken up by NK cells, which was affected by low temperature and the incubation time, as described in other articles. ${ }^{20}$ Moreover, the uptake capacity of NK cells was significantly increased by transforming growth factor (TGF)- $\beta$ treatment (Figure 4e). It is important to note that as shown in Figure 4f, HBV rcDNA and HBV RNA were detected in NK cells exposed to HBV-positive exosomes, which was consistent with the observations made using peripheral NK cells from CHB patients (Figure 4a). These findings indicate that exosomes can function as a carrier to transmit and deliver HBV components into NK cells, and this process can be regulated by cytokines correlated with NKcell dysfunction.

\section{HBV components inhibited NK-cell functions and cell viability}

To confirm whether HBV components directly interfere with NK-cell functions, NK-92 cells were transfected with the pLMP-HBV plasmid $\left(\mathrm{HBV}^{+} \mathrm{NK}-92\right)$. In this cell model, $\mathrm{HBV}^{+} \mathrm{NK}-92$ cells, similar to primary NK cells isolated from CHB patients, carried HBV rcDNA and HBV RNA (HBx and HBs/p) (Supplementary Figure 1). K562 and HepG2 tumor cell lines were used as target cells. The cytotoxicity mediated by $\mathrm{HBV}^{+}$NK-92 cells was $\sim 10 \%$ lower than the cytotoxicity mediated by $\mathrm{HBV}^{-}$NK-92 control cells (Figure 5a). In addition, reduced expression of $\mathrm{CD} 107 \mathrm{a}$ and the cytotoxic mediators perforin and Granzyme B (GramB) was observed (Figure 5b). Meanwhile, the intracellular levels of IFN- $\gamma$, but not TNF- $\alpha$, were downregulated in $\mathrm{HBV}^{+}$NK-92 cells (Figure 5c). Furthermore, compared to control cells, the proliferative ability of $\mathrm{HBV}^{+}$NK-92 cells was suppressed (Figure 5d), and cell cycle analysis showed that these cells arrested in G0/G1 phase (Figure 5e) and had increased apoptosis rates (Figure $5 \mathrm{f}$ ). These data indicate that HBV can directly disturb NK-cell functions and survival.

\section{HBV dampened RIG-I expression and the downstream signaling pathways in NK cells}

NK cells from $\mathrm{CHB}$ patients exhibit impaired responsiveness to activating signals. ${ }^{18}$ We further investigated how HBV affected NK cells and their signaling pathways. $\mathrm{HBV}^{+} \mathrm{NK}-92$ and control cells were stimulated with poly (I:C), which mimics double-strand viral RNA and acts synergistically with IL-2 to induce IFN- $\gamma$ production by NK cells. ${ }^{21}$ As shown in Figure 6a, compared to $\mathrm{HBV}^{-}$NK-92 cells, the expression levels of CD107a and the cytotoxic mediators perforin and GramB, as well as the IFN- $\gamma$ expression levels, were reduced in $\mathrm{HBV}^{+}$ NK-92 cells in response to poly (I:C) stimulation (Figure 6b).

Upon the recognition of viral components or pathogenassociated molecule patterns, pattern-recognition receptor
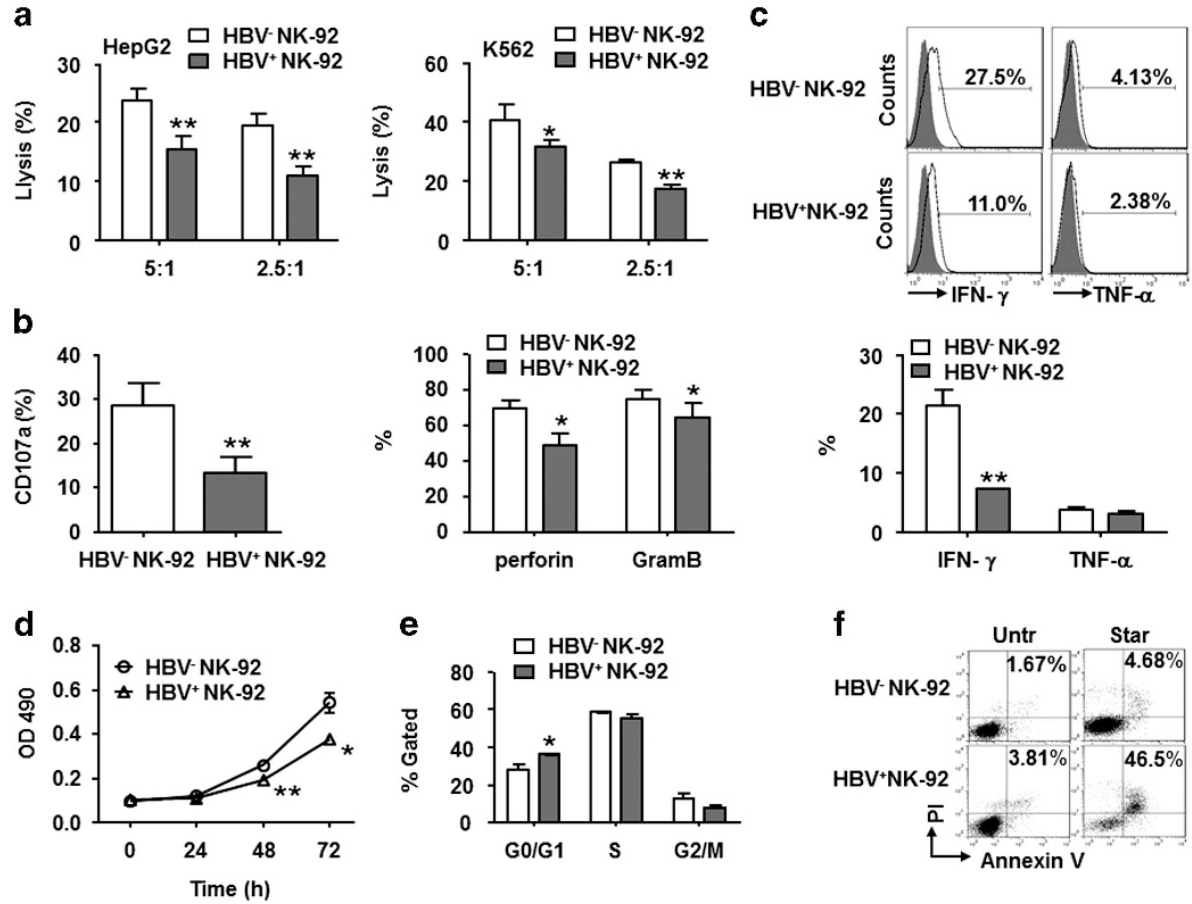

Figure 5 HBV components inhibited NK cell function and cell viability. Cytotoxicity was evaluated using a CFSE/7AAD assay (a), and the levels of the degranulation molecule CD107a and the intracellular cytotoxic mediators perforin and $\mathrm{GramB}^{(\mathbf{b})}$ in $\mathrm{HBV}^{+} \mathrm{NK}^{-92}$ and $\mathrm{HBV}^{-}$NK-92 cells were analyzed using flow cytometry. (c) The intracellular levels of IFN- $\gamma$, TNF- $\alpha$ in HBV $\mathrm{HK}^{+}-92$ and HBV- NK-92 cells were analyzed using flow cytometry. (d) The proliferation of $\mathrm{HBV}^{+}$NK-92 and HBV- NK-92 cells was analyzed using an MTT assay. (e) The cell cycle of $\mathrm{HBV}^{+}$NK-92 and HBV- NK-92 cells was analyzed using flow cytometry. (f) The apoptotic rate of HBV ${ }^{+} \mathrm{NK}^{-}-92$ and HBV $^{-}$NK-92 cells after serum starvation was analyzed via flow cytometry using PI and APC-labeled Annexin V. One representative of three independent experiments is shown. The data are expressed as the mean \pm s.e.m. from at least three independent experiments. ${ }^{*} P<0.05$, ${ }^{* *} P<0.01$. HBV, hepatitis B virus; NK, natural killer; Star, serum starvation; Untr, untreated. 
a

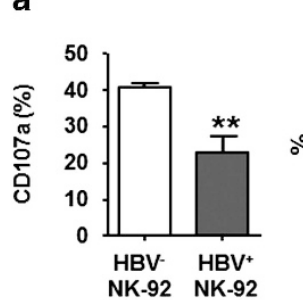

d

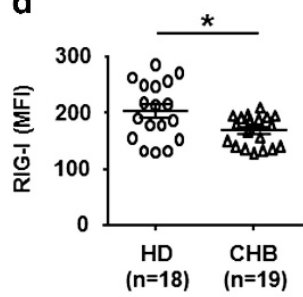

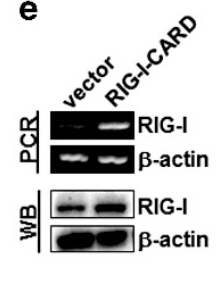

b

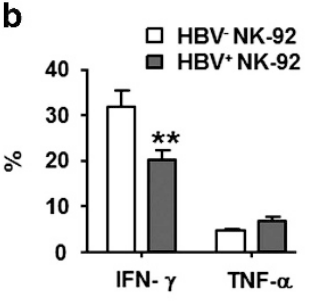

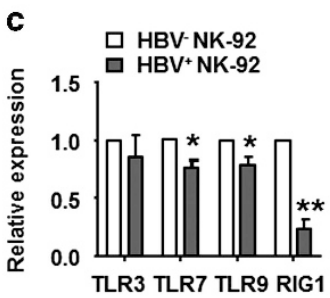

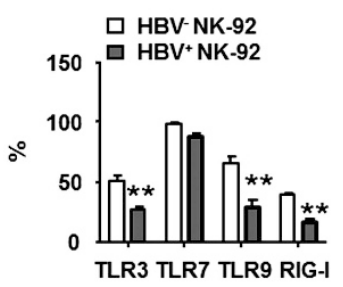

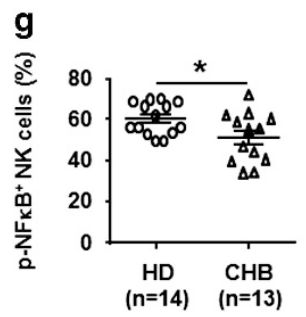
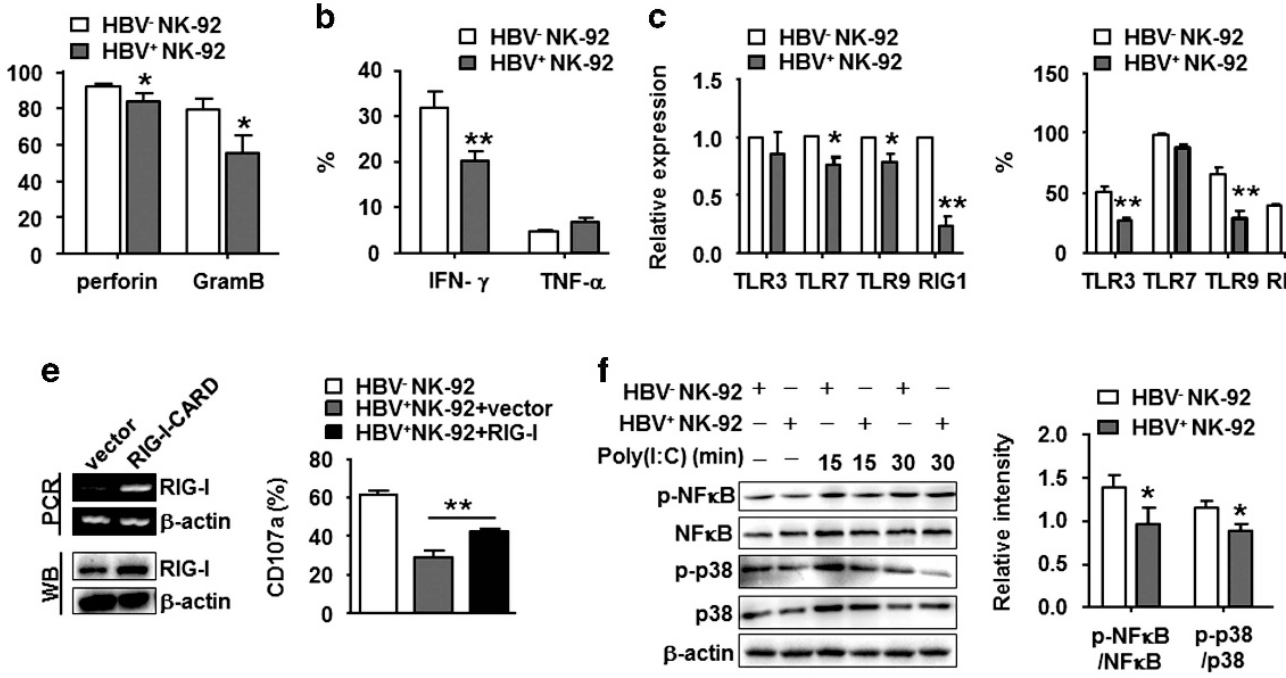

Figure 6 HBV dampened the expression of RIG-I and its downstream signaling pathway in NK cells. (a) The levels of CD107a and molecules associated with cytolysis, perforin and GramB, in $\mathrm{HBV}^{+} \mathrm{NK}-92$ cells in response to poly (I:C) stimulation were analyzed using flow cytometry. (b) The intracellular levels of IFN- $\gamma$ and TNF- $\alpha$ in $\mathrm{HBV}^{+} \mathrm{NK}-92$ cells in response to poly (I:C) stimulation were analyzed using flow cytometry. (c) TLR and RIG-I mRNA (left) and protein (right) levels in HBV+ NK-92 and control cells. (d) The RIG-I expression levels in $\mathrm{CD}_{56}{ }^{+} \mathrm{CD} 3^{-} \mathrm{NK}$ cells from $\mathrm{HD}$ and $\mathrm{CHB}$ patients were assessed through flow cytometry. (e) The pcDNA5-RIG-I CARD plasmid was used to transfect $\mathrm{HBV}^{+}$NK-92 cells (left), and the analysis of the CD107a expression is shown (right). (f) WB blot analysis for NF-kB (p65) and p38 activation in $\mathrm{HBV}^{+}$NK-92 cells in response to poly (I:C) stimulation (left). The densitometric analysis for p-NF-kB and p-p38 expression is normalized to their total protein levels in NK-92 cells stimulated with poly (I:C) for 15 min, and the control group of unstimulated $\mathrm{HBV}^{-}$NK-92 cells was set as 1 (right). (g) NF-kB (p65) and p38 phosphorylation levels in primary $\mathrm{CD}^{-} 6^{+} \mathrm{CD} 3^{-} \mathrm{NK}^{-}$cells from HD and CHB patients. The RIG-I expression (h), NFKB and p38 phosphorylation levels (i) in NK cells from HD were analyzed using flow cytometry after CHB exosome treatment. One representative of at least three independent experiments is shown. The data are expressed as the mean \pm s.e.m. ${ }^{*} P<0.05,{ }^{*} P<0.01$. CHB, chronic hepatitis B; HBV, hepatitis B virus; HD, healthy donors; NK, natural killer; WB, western blotting.

(PRR) activation induces inflammatory cytokines, such as type I-IFNs, to control viral replication and dissemination, and subsequently initiate adaptive immunity. ${ }^{22}$ Therefore, we analyzed whether HBV nucleic acids influenced the expression of any PRRs associated with virus recognition in NK cells, including TLR3, TLR7, TLR9 and RIG-I. ${ }^{21,23}$ As shown in Figure 6c, the expression level of PRRs, especially RIG-I, in NK-92 cells was obviously downregulated by pLMP-HBV plasmid transfection. Consistently, the level of RIG-I expressed by primary NK cells from $\mathrm{CHB}$ patients was also decreased compared to $\mathrm{NK}$ cells from healthy donors (Figure 6d). To further confirm whether RIG-I is involved in NK-cell dysfunction during $\mathrm{HBV}$ infection, $\mathrm{HBV}^{+} \mathrm{NK}-92$ cells were transfected with a plasmid containing the caspase-recruitment domain of RIG-I. As shown in Figure 6e, the reduced CD107a expression in NK cells during $\mathrm{HBV}$ infection was partly restored by RIG-I overexpression.
The NF- $\kappa \mathrm{B}$ and MAPK pathways, downstream of PRRs including RIG-I, were reported to be responsible for NKcell activation and cytokine production. ${ }^{21,24}$ We examined the signaling molecules associated with the activation of NF- $\kappa B$ and MAPK in NK-92 cells. As shown in Figure 6f, $\mathrm{NF}-\kappa \mathrm{B}$ and p38 MAPK phosphorylation levels were lower in $\mathrm{HBV}^{+}$NK-92 cells than in $\mathrm{HBV}^{-}$NK-92 cells with or without poly (I:C) treatment, but no significant changes were observed for the phosphorylation of ERK, c-Jun and JNK within the MAPK pathway (data not shown). Consistent with this, the NF- $\kappa \mathrm{B}$ and $\mathrm{p} 38$ MAPK phosphorylation levels in primary NK cells from $\mathrm{CHB}$ patients were lower than in NK cells from healthy donors (Figure $6 \mathrm{~g}$ ). Similar results were observed in primary NK cells from healthy donors treated with $\mathrm{HBV}^{+}$exosomes (Figure $6 \mathrm{~h}$ and i). These findings suggest that HBV might directly interfere with NK-cell function in a RIG-I-dependent manner, which dampens the activation of both NF- $\mathrm{B}$ and $\mathrm{p} 38$. 


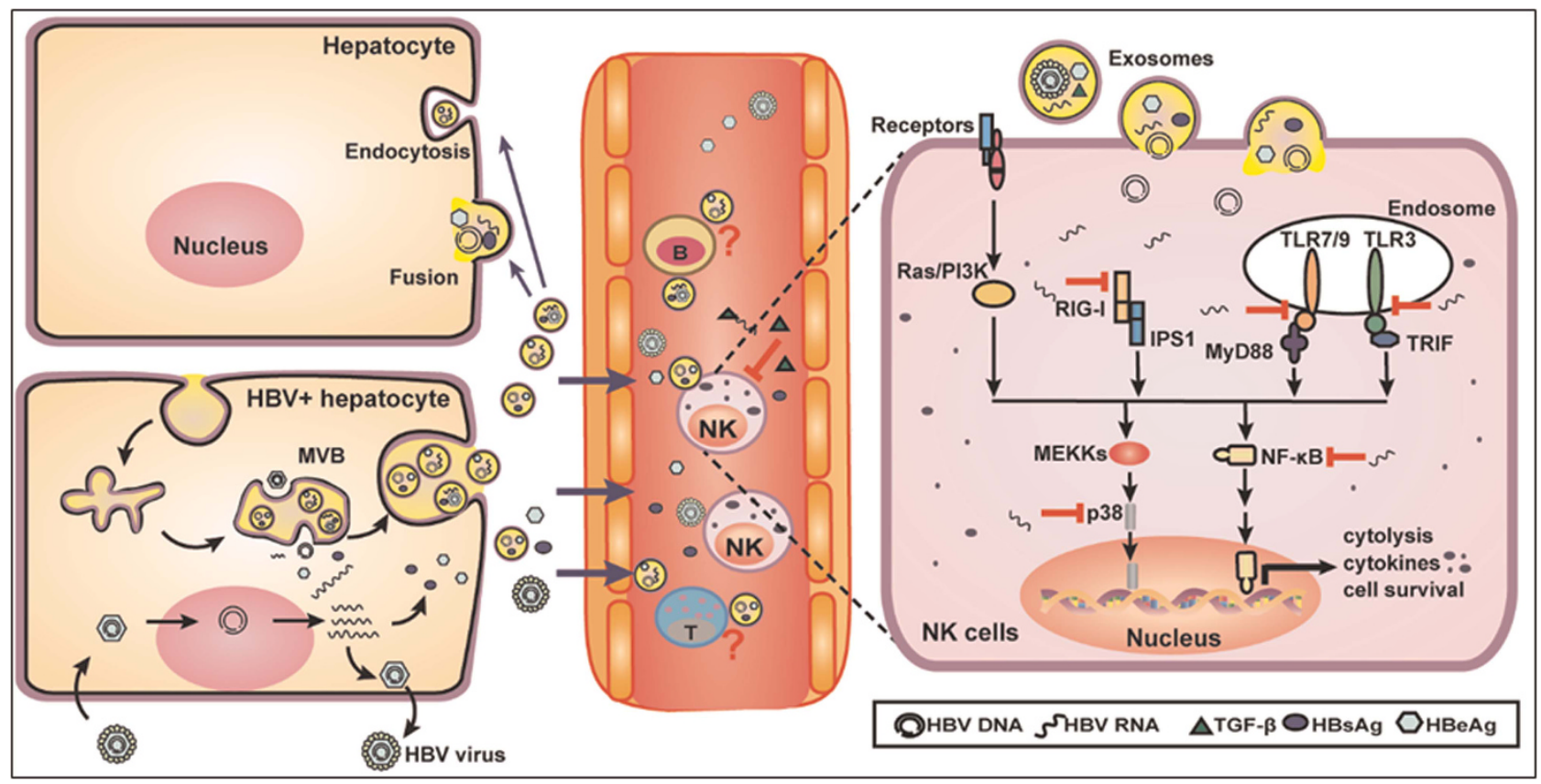

Figure 7 Schematic of exosome-mediated HBV transmission and NK cell dysfunction. In CHBV infection, exosomes are derived from the internal vesicles of multivesicular bodies (MVBs) of HBV-infected hepatocytes. MVBs fuse with the plasma membrane and release exosomes that contain HBV components. Then, these exosomes transmit HBV into naive hepatocytes and even NK cells. In NK cells, HBV nucleic acids transmitted by exosomes affect NK cytolytic activity, cytokine production, and cell proliferation. The underlying mechanisms are associated with RIG-I expression and NF-kB and p38 activation.

\section{DISCUSSION}

The exosome is an endogenous nanovesicle with a bilayer membrane that contains various proteins, lipids and nucleic acids, and plays an important role in many biological processes. ${ }^{25}$ Although the effects of exosomes in mediating HCV transmission between cells have been extensively demonstrated recently, $10,11,26$ the role of exosomes in HBV infection has not been clarified thus far.

In the present study, we found that the exosomes present in the serum of $\mathrm{CHB}$ patients contain both HBV nucleic acids and HBV proteins (Figure 1). HBV cccDNA was thought to be present in the nucleus with a much lower copy number than other HBV DNA/RNA. However, it is reported that some viruses, such as retroviruses, can hijack the exosomal machinery, bud inside MVBs and subsequently secrete within exosomes. ${ }^{27}$ Here, we speculate that the nuclei of hepatic parenchymal cells from CHB patients is disturbed by HBV infection, which results in HBV cccDNA flowing into the cytoplasm and then budding inside the exosomes. Moreover, HBV-positive exosomes transmit HBV to uninfected hepatoma cells, which function as effectively as free virus within a HepG2.2.15 cell supernatant (Figure 2, Supplementary Movie S2). Recently, NTCP has been identified as a putative HBV receptor. ${ }^{5}$ Because HBV virions may be contaminated in the exosome fraction, we analyzed exosome-mediated HBV transmission to a NTCP-negative hepatocyte line, HepG2. The results show that the cells were $\mathrm{HBsAg}^{+}$and $\mathrm{HBcAg}^{+}$after 2 days exposure to $\mathrm{HBV}$-positive exosomes but negative when incubated with HepG2.2.15 cell supernatant
(Supplementary Figure 2), further supporting that exosomemediated HBV transmission occurs independently of HBV receptors. This finding shows that exosomes act as carriers of HBV virus, viral nucleic acid and viral proteins, as observed in HCV and HIV. ${ }^{6}$

NK cells represent the principal effector cell population involved in innate immune responses to viral infections, and NK cell dysfunction may contribute to viral persistence. ${ }^{28}$ Our results suggest that NK cells could be functionally impaired in CHB patients, with decreased cell cytotoxicity and IFN- $\gamma$ production (Figures $3 \mathrm{a}$ and $\mathrm{b}$ ). Generally, the upregulation of immunosuppressive factors, such as TGF- $\beta$, in HBV-infected hosts contributes to NK-cell dysfunction. ${ }^{14}$ Here, we found that HBV-positive exosomes inhibited the cytolytic activity and IFN- $\gamma$ production of primary NK cells from healthy donors (Figures $3 c$ and $d$ ), suggesting that HBV might influence NK-cell function via exosomes. Although there is still controversy, HBV nucleic acids have been reported to be detectable in peripheral NK cells using limiting dilution PCR or deep sequencing analysis of HBV genomes. ${ }^{29,30}$ In the present study, we also found that HBV nucleic acids were present in NK cells from CHB patients (Figure 4). However, the HBV cccDNA present in exosomes was not detected in either primary NK cells from $\mathrm{CHB}$ patients or NK cells from healthy donors exposed to HBV-positive exosomes (Figures $4 \mathrm{a}$ and f). Untergasser et al. ${ }^{17}$ found that even though circulating DCs can take up HBV antigens and HBV DNA, these DCs cannot support the nucleocytoplasmic transport or replication of HBV. Therefore, we speculate that HBV cccDNA transferred by exosomes would 
be removed by intrinsic complex mechanisms of NK cells or that NK cells do not sustain HBV replication. The precise mechanisms need more intensive molecular biologic studies.

It has been reported that NK cells can take up exosomes released by tumor cells, resulting in phenotypic and functional changes of NK cells. ${ }^{31}$ Interestingly, we detected HBV nucleic acids in NK cells from healthy donors after treatment with HBV-positive exosomes. We also found that the immunosuppressive factor TGF- $\beta$ enhanced the uptake of exosomes by NK cells (Figure 4). Similar phenomena were observed when NK-92 cells were transfected with the pLMP-HBV plasmid (Supplementary Figure 1). In this cell model, HBV genome transfection decreased NK-92 cell cytotoxicity and CD107a expression, accompanied by the reduction of IFN- $\gamma$, perforin and GramB, similar to what was observed in primary NK cells isolated from $\mathrm{CHB}$ patients. Meanwhile, $\mathrm{HBV}^{+} \mathrm{NK}-92$ cells displayed reduced proliferation ability, cell cycle arrest and apoptosis (Figure 5), consistent with the reduced numbers of circulating NK cells in CHB patients. ${ }^{32,33}$ These results confirm that HBV-positive exosomes can be taken up by NK cells, and that HBV nucleic acids present in NK cells contribute to NK cell dysfunction and diminished NK cell survival.

NK cell activation is controlled by a dynamic balance between the complementary and antagonistic pathways that are initiated upon ligand binding. ${ }^{24}$ The NF- $\mathrm{BB}$ and MAPK pathways broadly participate in lymphocyte proliferation, maturation and activation. ${ }^{24}$ In $\mathrm{CHB}$ patients, PRRs are downregulated in peripheral blood monocytes, hepatocytes and Kupffer cells, with decreased type I IFNs and cytokine production in response to TLR ligands. ${ }^{34,35}$ We observed the suppression of RIG-I expression, as well as the inhibition of p38 and NF- $\kappa \mathrm{B}$ activation, in primary NK cells from $\mathrm{CHB}$ patients and in primary NK cells from healthy donors after treatment with exosomes from $\mathrm{CHB}$ patients (Figure 6). Therefore, these results indicate that $\mathrm{HBV}$ nucleic acids disrupt $\mathrm{NK}$-cell function partly by reducing RIG-I expression and inhibiting NF- $\mathrm{BB}$ and p38 activation, dampening NK-cell responses to the intermediate RNA products derived from $\mathrm{HBV}$.

In summary, our findings provide mechanistic insight into the exosome-mediated transmission of $\mathrm{HBV}$ in a viral receptor-independent manner (illustrated in Figure 7). We found that exosomes shuttle HBV into uninfected hepatocyte cells as efficiently as free-virus infection. In addition, HBV can be transferred into non-permissive NK cells via exosomes. As a result, HBV nucleic acid induces the functional tolerance of NK cells by downregulating RIG-I expression and inactivating the NF- $\kappa \mathrm{B}$ and $\mathrm{p} 38$ pathways. These observations suggest that exosomes may serve as important regulators of HBV transmission and may be involved in escaping innate immunity.

\section{CONFLICT OF INTEREST}

The authors declare no conflict of interest.

\section{ACKNOWLEDGEMENTS}

This work was supported by grants from the National Basic Research Program of China (No. 2013CB531503), the Natural Science Foundation of China (Nos. 81172789 and 30972692).

\section{AUTHOR CONTRIBUTIONS}

Y-LY and Q-JH designed, performed and analyzed experiments, and wrote the manuscript; Z-HH performed experiments; Z-GT, CZ and JZ provided reagents and technical support; JZ designed and analyzed experiments, and edited the manuscript.

1 Lavanchy D. Hepatitis B virus epidemiology, disease burden, treatment, and current and emerging prevention and control measures. $J$ Viral Hepat 2004; 11: 97-107.

2 McMahon BJ. The natural history of chronic hepatitis B virus infection. Hepatology 2009; 49: S45-S55.

3 McMahon BJ. Chronic hepatitis B virus infection. Med Clin North Am 2014; 98: 39-54.

4 Glebe D, Urban S. Viral and cellular determinants involved in hepadnaviral entry. World J Gastroenterol 2007; 13: 22-38.

5 Yan H, Zhong G, Xu G, He W, Jing Z, Gao Z et al. Sodium taurocholate cotransporting polypeptide is a functional receptor for human hepatitis $B$ and D virus. Elife 2012; 1: e00049.

6 Chahar HS, Bao X, Casola A. Exosomes and their role in the life cycle and pathogenesis of RNA viruses. Viruses 2015; 7: 3204-3225.

7 Lee Y, El Andaloussi S, Wood MJ. Exosomes and microvesicles: extracellular vesicles for genetic information transfer and gene therapy. Hum Mol Genet 2012; 21: R125-R134.

8 Meckes Jr DG, Raab-Traub N. Microvesicles and viral infection. J Virol 2011; 85: 12844-12854.

9 Alenquer M, Amorim MJ. Exosome biogenesis, regulation, and function in viral infection. Viruses 2015; 7: 5066-5083.

10 Bukong TN, Momen-Heravi F, Kodys K, Bala S, Szabo G. Exosomes from hepatitis $\mathrm{C}$ infected patients transmit HCV infection and contain replication competent viral RNA in complex with Ago2-miR122HSP90. PLoS Pathog 2014; 10: e1004424.

11 Dreux M, Garaigorta U, Boyd B, Decembre E, Chung J, Whitten-Bauer $\mathrm{C}$ et al. Short-range exosomal transfer of viral RNA from infected cells to plasmacytoid dendritic cells triggers innate immunity. Cell Host Microbe 2012; 12: 558-570.

$12 \mathrm{Li}$ J, Liu K, Liu Y, Xu Y, Zhang F, Yang $\mathrm{H}$ et al. Exosomes mediate the cell-to-cell transmission of IFN-alpha-induced antiviral activity. Nat Immunol 2013; 14: 793-803.

13 Peppa D, Micco L, Javaid A, Kennedy PT, Schurich A, Dunn C et al. Blockade of immunosuppressive cytokines restores NK cell antiviral function in chronic hepatitis B virus infection. PLoS Pathog 2010; 6: e1001227.

14 Sun C, Fu B, Gao Y, Liao X, Sun R, Tian Z et al. TGF-betal downregulation of NKG2D/DAP10 and 2B4/SAP expression on human NK cells contributes to HBV persistence. PLoS Pathog 2012; 8: e1002594.

$15 \mathrm{Wu} \mathrm{L}$, Zhang $\mathrm{C}$, Zhang J. HMBOX1 negatively regulates NK cell functions by suppressing the NKG2D/DAP10 signaling pathway. Cell Mol Immunol 2011; 8: 433-440.

16 Yang D, Zuo C, Wang X, Meng X, Xue B, Liu N et al. Complete replication of hepatitis $B$ virus and hepatitis $C$ virus in a newly developed hepatoma cell line. Proc Natl Acad Sci U S A 2014; 111: E1264-E1273.

17 Untergasser A, Zedler U, Langenkamp A, Hosel M, Quasdorff M, Esser $\mathrm{K}$ et al. Dendritic cells take up viral antigens but do not support the early steps of hepatitis B virus infection. Hepatology 2006; 43: 539-547.

18 Tjwa ET, van Oord GW, Hegmans JP, Janssen HL, Woltman AM. Viral load reduction improves activation and function of natural killer cells in patients with chronic hepatitis B. J Hepatol 2011; 54: 209-218.

19 Zech D, Rana S, Buchler MW, Zoller M. Tumor-exosomes and leukocyte activation: an ambivalent crosstalk. Cell Commun Signal 2012; 10: 37. 
20 Tian T, Zhu YL, Hu FH, Wang YY, Huang NP, Xiao ZD. Dynamics of exosome internalization and trafficking. J Cell Physiol 2013; 228 $1487-1495$

21 Girart MV, Fuertes MB, Domaica Cl, Rossi LE, Zwirner NW. Engagement of TLR3, TLR7, and NKG2D regulate IFN-gamma secretion but not NKG2D-mediated cytotoxicity by human NK cells stimulated with suboptimal doses of IL-12. J Immunol 2007; 179: 3472-3479.

22 Kawai T, Akira S. Innate immune recognition of viral infection. Nat Immunol 2006; 7: 131-137.

23 Perrot I, Deauvieau F, Massacrier C, Hughes N, Garrone P, Durand I et al. TLR3 and Rig-like receptor on myeloid dendritic cells and Rig-like receptor on human NK cells are both mandatory for production of IFN-gamma in response to double-stranded RNA. J Immunol 2010; 185: 2080-2088.

24 Vivier E, Nunes JA, Vely F. Natural killer cell signaling pathways. Science 2004; 306: 1517-1519.

25 Hosseini HM, Fooladi AA, Nourani MR, Ghanezadeh F. The role of exosomes in infectious diseases. Inflamm Allergy Drug Targets 2013; 12: 29-37.

26 Ramakrishnaiah V, Thumann C, Fofana I, Habersetzer F, Pan Q, de Ruiter PE et al. Exosome-mediated transmission of hepatitis $\mathrm{C}$ virus between human hepatoma Huh7.5 cells. Proc Natl Acad Sci USA 2013; 110: 13109-13113.

27 Thery C, Ostrowski M, Segura E. Membrane vesicles as conveyors of immune responses. Nat Rev Immunol 2009; 9: 581-593.

28 Mondelli MU, Varchetta S, Oliviero B. Natural killer cells in viral hepatitis: facts and controversies. Eur J Clin Invest 2010; 40: 851-863.

29 Trippler M, Meyer zum Buschenfelde KH, Gerken G. HBV viral load within subpopulations of peripheral blood mononuclear cells in HBV infection using limiting dilution PCR. J Virol Methods 1999; 78: 129-147.

30 Lee Z, Nishikawa S, Gao S, Eksteen JB, Czub M, Gill MJ et al. Detection of hepatitis B virus (HBV) genomes and HBV drug resistant variants by deep sequencing analysis of HBV genomes in immune cell subsets of HBV mono-infected and/or human immunodeficiency virus type-1 (HIV-1) and HBV co-infected individuals. PLoS One 2015; 10: e0137568.
31 Clayton A, Mitchell JP, Court J, Linnane S, Mason MD, Tabi Z. Human tumor-derived exosomes down-modulate NKG2D expression. J Immunol 2008; 180: 7249-7258.

32 Oliviero B, Varchetta S, Paudice E, Michelone G, Zaramella M, Mavilio D et al. Natural killer cell functional dichotomy in chronic hepatitis B and chronic hepatitis C virus infections. Gastroenterology 2009; 137: 1151-1160 1160, e1151-1157.

33 Zou Z, Xu D, Li B, Xin S, Zhang Z, Huang L et al. Compartmentalization and its implication for peripheral immunologically-competent cells to the liver in patients with HBV-related acute-on-chronic liver failure. Hepatol Res 2009; 39: 1198-1207.

34 Wu J, Meng Z, Jiang M, Pei R, Trippler M, Broering R et al. Hepatitis B virus suppresses toll-like receptor-mediated innate immune responses in murine parenchymal and nonparenchymal liver cells. Hepatology 2009; 49: 1132-1140.

35 Yu S, Chen J, Wu M, Chen H, Kato N, Yuan Z. Hepatitis B virus polymerase inhibits RIG-I- and Toll-like receptor 3-mediated beta interferon induction in human hepatocytes through interference with interferon regulatory factor 3 activation and dampening of the interaction between TBK1/IKKepsilon and DDX3. J Gen Virol 2010; 91: 2080-2090.

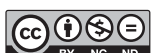

This work is licensed under a Creative Commons Attribution-NonCommercial-NoDerivs 4.0 International License. The images or other third party material in this article are included in the article's Creative Commons license, unless indicated otherwise in the credit line; if the material is not included under the Creative Commons license, users will need to obtain permission from the license holder to reproduce the material. To view a copy of this license, visit http://creativecommons.org/licenses/by-nc-nd/4.0/

Supplementary Information for this article can be found on the Cellular \& Molecular Immunology website (http://www.nature.com/cmi) 